\begin{tabular}{|c|c|c|}
\hline \multirow{3}{*}{$\begin{array}{r}\text { Case Reports in } \\
\text { Gastroenterology }\end{array}$} & \multirow{2}{*}{\multicolumn{2}{|c|}{ Case Rep Gastroenterol 2014;8:257-263 }} \\
\hline & & \\
\hline & $\begin{array}{l}\text { DOI: } 10.1159 / 000367590 \\
\text { Published online: September 3, } 2014\end{array}$ & $\begin{array}{l}\text { (c) } 2014 \text { S. Karger AG, Basel } \\
\text { 1662-0631/14/0083-0257\$39.50/0 } \\
\text { www.karger.com/crg }\end{array}$ \\
\hline & \multicolumn{2}{|c|}{$\begin{array}{l}\text { This is an Open Access article licensed under the terms of the Creative Commons } \\
\text { Attribution-NonCommercial } 3.0 \text { Unported license (CC BY-NC) (www.karger.com/OA } \\
\text { license), applicable to the online version of the article only. Distribution permitted for non } \\
\text { commercial purposes only. }\end{array}$} \\
\hline
\end{tabular}

\title{
A Case of a Gastrointestinal Stromal Tumor with Skeinoid Fibers of the Sigmoid Colon
}

\author{
Tetsuo Sumi $^{a} \quad K^{2}$ ji Katsumata ${ }^{d}$ Makoto Shibuya $^{b}$ \\ Sou Katayanagi ${ }^{a}$ Kenichi Iwasaki $^{\mathrm{a}}$ Kazuhiko Kasuya $^{\mathrm{d}}$ \\ Hiromi Serizawa ${ }^{c}$ Motohide Shimazu ${ }^{a}$ Akihiko Tsuchida ${ }^{d}$ \\ ${ }^{a}$ Department of Gastroenterological Surgery and Transplant Surgery, ${ }^{b}$ Central Clinical \\ Laboratory, 'Department of Pathology, Tokyo Medical University Hachioji Medical Center, \\ and ${ }^{\mathrm{d}}$ Third Department of Surgery, Tokyo Medical University, Tokyo, Japan
}

\section{Key Words}

Gastrointestinal stromal tumors $\cdot$ Sigmoid colon $\cdot$ Skeinoid fiber

\begin{abstract}
An 80-year-old man was diagnosed with rectal cancer and underwent Hartmann's procedure. Although no tumors were identified during the preoperative examination, gross examination of the resected specimen incidentally revealed a submucosal tumor that was $9 \mathrm{~mm}$ in diameter at the oral side and located in the proximal stump of the specimen from the sigmoid colon. We suspected a concurrent gastrointestinal stromal tumor (GIST) and performed a histopathological examination. An L-shaped nodular lesion measuring $9 \times 6 \mathrm{~mm}$ was histologically composed of a patternless proliferation of spindle cells intermingled with eosinophilic globules. Cellular atypia, prominent mitotic figures and necrotic foci were not observed in the nodule. The spindle cells were positive for CD34, CD117 and vimentin, but negative for CD56, smooth muscle actin and S-100 protein. MIB-1 positivity was estimated to be as low as approximately $1-2 \%$. Electron microscopy showed a bundle of wool-like fibers with a periodicity of approximately $40 \mathrm{~nm}$. We therefore considered the lesion to be a low-risk GIST with skeinoid fibers in the large intestine. Although numerous previous reports have reported skeinoid fibers in the stomach and small intestines, there have been only 9 cases (including the present case) of skeinoid fibers in the large intestine.

(c) 2014 S. Karger AG, Basel
\end{abstract}


Sumi et al:: A Case of a Gastrointestinal Stromal Tumor with Skeinoid Fibers of the Sigmoid Colon

\section{Introduction}

Skeinoid fibers, which were discovered in small intestinal stromal tumors and named by Min in 1991 [1], are collagen fibers that resemble bundles of wool, have a periodicity of 41$48 \mathrm{~nm}$ and form aggregates of tangled, fuzzy fibrils when observed using electron microscopy. They have similar stainability to collagen fibers. They were initially thought to have important embryological, differential and morphological significance. However, after being reported in the stomach and small intestine in numerous cases, skeinoid fibers gained clinical significance as a useful prognostic indicator for small intestinal tumors [2]. New immunohistological findings were also reported [3]. While Min [1] first reported skeinoid fibers in 8 cases in tumor studies comprising more than 5,000 cases, more recent studies have shown higher likelihoods of discovery [3-7]. Only 9 cases (including the present case) of skeinoid fibers in the large intestine have been reported [4, 8] (table 1). Although it was thought to be rare when first reported, we appear to be approaching the true nature of the disease as more studies accumulate. Here, we report a case of resection of a sigmoid colon mesenchymal tumor with skeinoid fibers in an 80-year-old man. We report the patient's characteristics, details of his clinical course, pathological immunohistological findings and morphological findings from electron microscopy, and discuss the relevant literature.

\section{Case Report}

An 80-year-old man presented with the chief complaint of bloody stools. The patient had a history of asthma for which he was on oral medication. In 2009, he came to our hospital for examination of bloody stool that had persisted for 2 months. The lower margin of a tumor was palpable at AV $6 \mathrm{~cm}$ in digital rectal examination. Upper rectal cancer was diagnosed using lower gastrointestinal endoscopy and a contrast enema, and the patient underwent Hartmann's procedure. Although no tumors were identified during the preoperative colonoscopy, barium enema examination or computed tomography, gross examination of the resected specimen incidentally revealed a submucosal tumor that was $9 \mathrm{~mm}$ in diameter at the oral side of the tumor and located in the proximal stump of the specimen from the sigmoid colon (fig. 1a). We suspected a concurrent gastrointestinal stromal tumor (GIST) and performed a histopathological examination.

The histopathological examination was conducted with formalin-fixed paraffin-embedded sections with H\&E and immunohistochemical staining. An electron microscopic examination was conducted using an ultrathin section derived from the paraffin-embedded blocks. The histological characteristics of the cancer lesion included an invasive proliferation of atypical cells arranged in a papillotubular structure, suggesting a well-differentiated adenocarcinoma. The lesion reached the subserosal tissue, and focal vascular permeation was observed. Lymph node metastasis was not observed. Although no tumors were identified during the preoperative examination, gross examination of the resected specimen incidentally revealed an L-shaped submucosal nodule measuring $9 \times 6 \mathrm{~mm}$ on a cut surface of the proximal region located apart from the cancer and near the proximal stump of the resected specimen (fig. 1a, b). An L-shaped well-demarcated nodular lesion was also located in the subserosal layers, and histological examination revealed a patternless proliferation of spindle cells with moderately increased cellularity intermingled with eosinophilic round or club-shaped globules. In addition, there was positive staining for periodic acid-Schiff (PAS) in the globules (fig. 1d). However, we did not observe nuclear atypia, increased mitotic activity or necrotic foci in the lesion. Immunohistochemically, the spindle cells were positive 
Sumi et al.: A Case of a Gastrointestinal Stromal Tumor with Skeinoid Fibers of the Sigmoid Colon

for CD34 (fig. 2a), CD117 (c-kit, fig. 2b) and vimentin (fig. 2d), but negative for CD56 (fig. 2e), smooth muscle actin (fig. 2f) and S-100 protein (fig. 2g). The eosinophilic globules were positive for type VI collagen (fig. 2c). The MIB-1 positivity was estimated to be as low as approximately 1-2\%. Electron microscopy of the globules showed a bundle of wool-like fibers with a periodicity of approximately $40 \mathrm{~nm}$ (fig. 3). We therefore considered this to be a low-risk GIST with skeinoid fibers (fig. 1b, c).

The postoperative prognosis was favorable, and the patient was discharged 3 weeks after the surgery.

\section{Discussion}

In 1991, Min [1] discovered collagen fibers resembling bundles of wool in electron microscopy in 3 of 8 cases of small intestinal stromal tumors; he named these fibers skeinoid fibers. Owing to the presence of skeinoid fibers in neurogenic spindle cell tumors, tumors with skeinoid fibers are assumed to be neurogenic.

Skeinoid fibers in light microscopy appear as homogenous eosinophilic globules, are strongly PAS-positive, are stained bright blue owing to their cytochromes, and are not stained by phosphotungstic acid hematoxylin or Elastica van Gieson [1]. However, Tsutsumi et al. [9] reported that they are stained by type VI collagen. Owing to histological findings in the present case that reflected the typical characteristics of skeinoid fibers, we determined that skeinoid fibers were present.

While maximum tumor diameter and the number of cells demonstrating mitotic activity and counts are useful prognostic factors for GIST, the presence of skeinoid fibers has also been reported as a prognostic factor. In examinations of small intestinal GISTs by Brainard and Goldblum [10] $(\mathrm{n}=39)$ and Miettinen et al. [5] $(\mathrm{n}=906)$, favorable prognoses were reported for cases in whom skeinoid fibers were observed. This may be related to the low level of mitotic activity frequently reported in cases with skeinoid fibers [2].

Skeinoid fibers were considered to be an indicator of small intestinal stromal tumor cell division when first discovered, and they were considered to be rare. Despite the increased detection in multiple organs, there are numerous reports of the presence of skeinoid fibers in the stomach and small intestine and only a few of their presence in the large intestine. A PubMed search using the key word phrase 'skeinoid fibers' yielded 7 cases of skeinoid fibers in the large intestine reported by Agaram et al. [4] and 1 case by Padberg et al. [8]. Although there are slight differences in the reports, we could consider that skeinoid fibers are present in approximately $30-50 \%$ of small intestinal GIST cases [3-7]. In contrast, there is large variation in the observed incidence of skeinoid fibers in the large intestine, ranging from 5 to 78\%; however, when the four studies that we found regarding large intestinal GISTs are considered together, skeinoid fibers were observed in a total of 7 out of 33 cases $(21 \%)[3,4$, 6, 7]. Agaram et al. [4] indicated that the incidence of skeinoid fibers is not low. Therefore, the scarcity of reports on skeinoid fibers may be due to the low frequency of GIST itself in all sites. However, if attention is given to findings of skeinoid fibers in the stomach and small intestine, reports of skeinoid fibers in the large intestine may also increase. In order to analyze the makeup of skeinoid fibers, the accumulation of individual cases is necessary.

Although we were unable to identify the diagnosis preoperatively, we encountered a case in whom a submucosal tumor was diagnosed from a specimen resected during rectal cancer surgery and in whom immunohistological examination revealed the presence of skeinoid fibers. The present case reaffirms the necessity of improving preoperative diagnosis and the importance of careful observation of resected specimens. 
Sumi et al.: A Case of a Gastrointestinal Stromal Tumor with Skeinoid Fibers of the Sigmoid Colon

\section{References}

1 Min KW: Skeinoid fibers: an ultrastructural marker of neurogenic spindle cell tumors. Ultrastruct Pathol 1991;15:603-611.

2 Miettinen M, Makhlouf H, Sobin LH, Lasota J: Gastrointestinal stromal tumors of the jejunum and ileum: a clinicopathologic, immunohistochemical, and molecular genetic study of 906 cases before imatinib with long-term follow-up. Am J Surg Pathol 2006;30:477-489.

-3 Tazawa K, Tsukada K, Makuuchi H, Tsutsumi Y: An immunohistochemical and clinicopathological study of gastrointestinal stromal tumors. Pathol Int 1999;49:786-798.

4 Agaram NP, Baren A, Arkun K, Dematteo RP, Besmer P, Antonescu CR: Comparative ultrastructural analysis and KIT/PDGFRA genotype in 125 gastrointestinal stromal tumors. Ultrastruct Pathol 2006;30:443-452.

5 Miettinen M, Kopczynski J, Makhlouf HR, Sarlomo-Rikala M, Gyorffy H, Burke A, Sobin LH, Lasota J: Gastrointestinal stromal tumors, intramural leiomyomas, and leiomyosarcomas in the duodenum: a clinicopathologic, immunohistochemical, and molecular genetic study of 167 cases. Am J Surg Pathol 2003;27:625-641.

-6 Orosz Z, Tornóczky T, Sápi Z: Gastrointestinal stromal tumors: a clinicopathologic and immunohistochemical study of 136 cases. Pathol Oncol Res 2005;11:11-21.

7 Hasegawa T, Matsuno Y, Shimoda T, Hirohashi S: Gastrointestinal stromal tumor: consistent CD117 immunostaining for diagnosis, and prognostic classification based on tumor size and MIB-1 grade. Hum Pathol 2002;33:669-676.

8 Padberg BC, Emmermann A, Zornig C, Germer M, Schröder S: Leiomyomatosis of the colon: case report and literature review. Pathologe 2007;28:161-165.

-9 Tsutsumi Y, Tazawa K, Shibuya M: Type VI collagen immunoreactivity in skeinoid fibers in small intestinal stromal tumors. Pathol Int 1999;49:836-839.

10 Brainard JA, Goldblum JR: Stromal tumors of the jejunum and ileum: a clinicopathologic study of 39 cases. Am J Surg Pathol 1997;21:407-416.

Table 1. Reported cases of skeinoid fibers in the colorectum

\begin{tabular}{llllll}
\hline Case & Reference & Year & Age & Gender & Site \\
\hline 1 & Agaram et al. [4] & 2006 & unknown & unknown & R \\
2 & Agaram et al. [4] & 2006 & unknown & unknown & R \\
3 & Agaram et al. [4] & 2006 & unknown & unknown & R \\
4 & Agaram et al. [4] & 2006 & unknown & unknown & R \\
5 & Agaram et al. [4] & 2006 & unknown & unknown & R \\
6 & Agaram et al. [4] & 2006 & unknown & unknown & R \\
7 & Agaram et al. [4] & 2006 & unknown & unknown & R \\
8 & Padberg et al. [8] & 2007 & 67 & male & R \\
9 & Our case & 2014 & 80 & male & S \\
\hline
\end{tabular}

$\mathrm{R}=$ Rectum; $\mathrm{S}$ = sigmoid colon. 
Sumi et al.: A Case of a Gastrointestinal Stromal Tumor with Skeinoid Fibers of the Sigmoid Colon
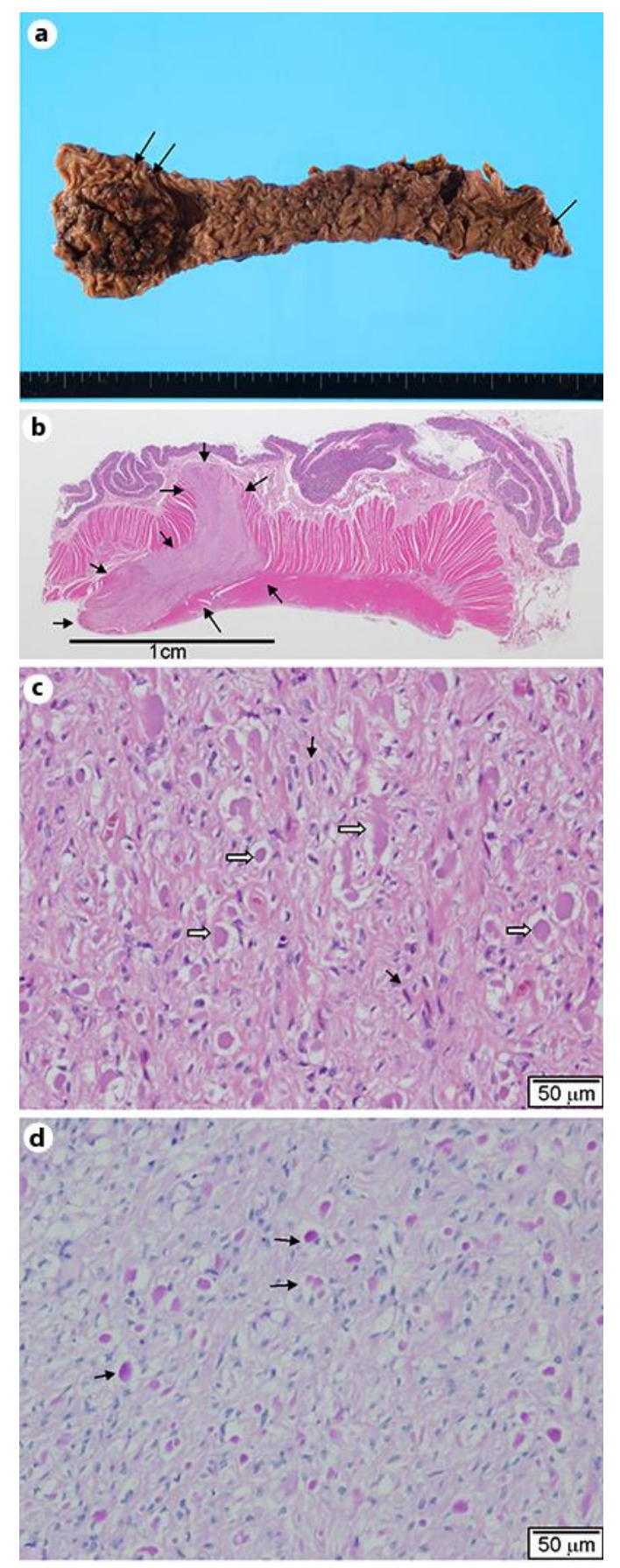

Fig. 1. a Excision specimen. The resected specimen following Hartmann's procedure for rectal cancer (double arrows). A submucosal tumor was observed in the vicinity of the proximal stump (arrow). b Loupe image. A reversed L-shaped $9 \times 6 \mathrm{~mm}$ nodular lesion in the muscularis propria (arrows). H\&E, $2 \times$ original magnification. c Photomicrograph of a submucosal tumor. Spindle cells (black arrows) with eosinophilic globules (white arrows). Neither nuclear atypia nor mitotic figures are observed. H\&E, 20× magnification. d PAS staining. Positive staining in the globules (arrows). $20 \times$ original magnification. 
Sumi et al.: A Case of a Gastrointestinal Stromal Tumor with Skeinoid Fibers of the Sigmoid Colon
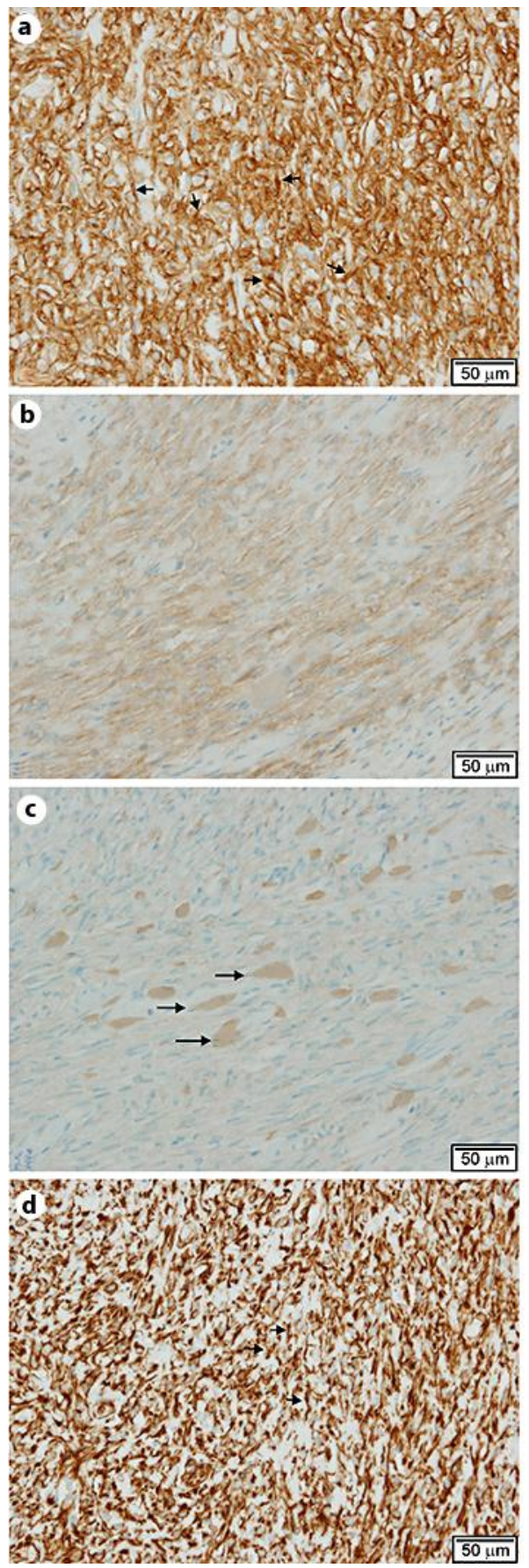
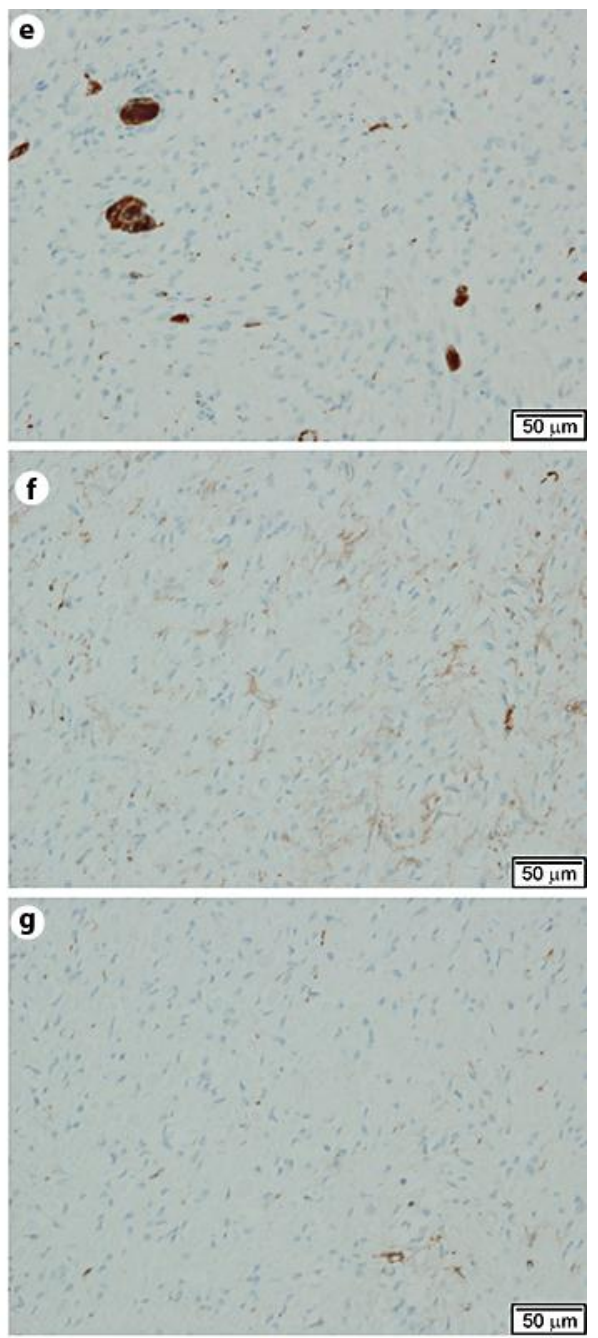

Fig. 2. a CD34. Spindle cells showed strong positive staining (arrows). 20× original magnification. b CD117. Spindle cells were positive for CD117. 20× original magnification. c Type VI collagen. Globules were positive for type VI collagen (arrows). 20× original magnification. d Vimentin. Spindle cells were positive for vimentin (arrows). 20× original magnification. e CD56. Spindle cells were negative for CD56; positive cells are intermingled with the pre-existing ganglion cells. $20 \times$ magnification. $f$ Smooth muscle actin. Spindle cells were negative for smooth muscle actin. $20 \times$ magnification. g S-100. Spindle cells were negative for S-100 protein. $20 \times$ magnification. 


\begin{tabular}{rl|l} 
Case Reports in & \multicolumn{2}{l}{ Case Rep Gastroenterol 2014;8:257-263 } \\
\cline { 2 - 3 } Gastroenterology & DOI: 10.1159/000367590 & $\begin{array}{l}\text { ○ 2014 S. Karger AG, Basel } \\
\text { www.karger.com/crg }\end{array}$ \\
\hline
\end{tabular}

Sumi et al.: A Case of a Gastrointestinal Stromal Tumor with Skeinoid Fibers of the Sigmoid Colon

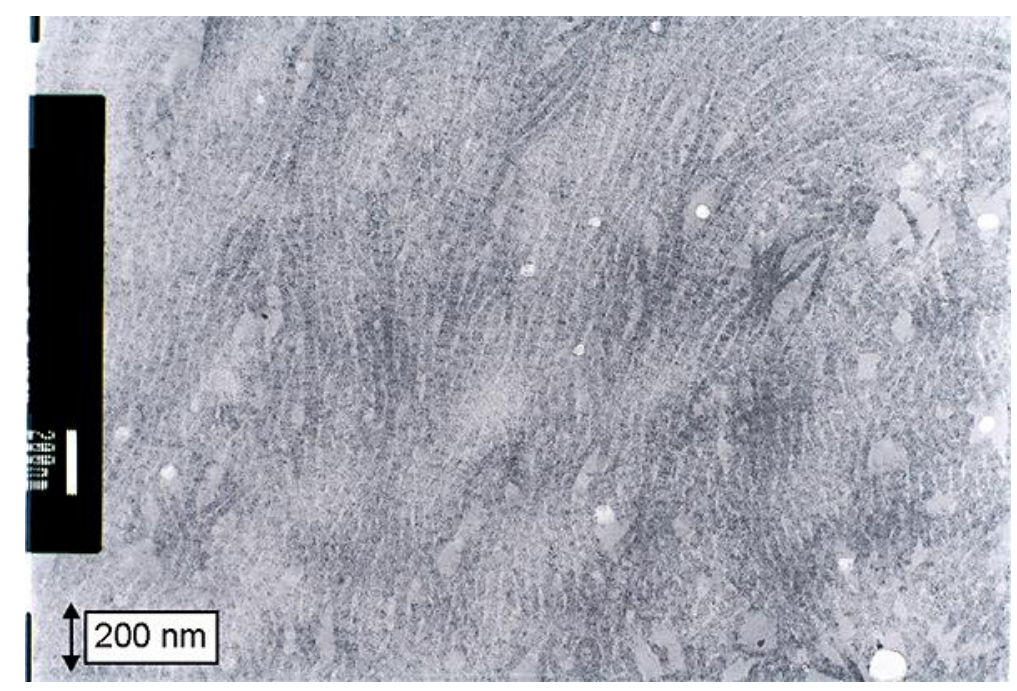

Fig. 3. Electron microscopic findings. Skeinoid fibers consist of tangles of curved fibrils with fuzzy borders resembling the appearance of skeins of yarn. 